\title{
Long non-coding RNA LINC00887 promotes progression of lung carcinoma by targeting the microRNA-206/NRP1 axis
}

\author{
LING-BIN XU ${ }^{1}$, BIAN-XIN BO $^{2}$, JIE XIONG $^{1}$, YA-JUAN REN ${ }^{1}$, \\ DONG HAN $^{1}$, SHENG-HONG WEI ${ }^{1}$ and XIAO-PING REN ${ }^{1}$
}

${ }^{1}$ The Second Department of Pulmonary and Critical Care Medicine, Shaanxi Provincial People's Hospital, Xi'an, Shaanxi
710068; ${ }^{2}$ Department of Critical Care Medicine, Zhouzhi Country People's Hospital, Xi'an, Shaanxi 710407, P.R. China

Received July 12, 2019; Accepted October 5, 2020

DOI: $10.3892 / 01.2020 .12348$

\begin{abstract}
Long non-coding RNAs (lncRNAs) have been reported to participate in multiple biological processes, including tumorigenesis. In the current study, the function of a novel lncRNA LINC00887 was investigated in lung carcinoma. For this purpose, LINC00887 expression was assessed by reverse-transcription quantitative PCR. Cell viability was determined by the CCK- 8 and EdU assays. Cell invasion, migration were assessed by the transwell and wound healing assays, respectively. A dual luciferase assay was used for analysis of the interaction between LINC00887 and miR-206, as well as the relationship of miR-206 with NRP1. A tumor xenograft study was performed to investigate the LINC00887-miR-206-NRP1 axis in vivo. The expression levels of LINC00887 were upregulated in lung carcinoma tissues and cells compared with adjacent tissues or normal cells (BEAS-2B). Knockdown LINC00887 significantly inhibited the proliferation, migration and invasion of lung carcinoma A549 and NCI-H460 cells. Furthermore, LINC00887 was identified as a competing endogenous RNA and to directly interact with miR-206. Mechanistically, miR-206 was demonstrated to regulate neuropilin-1 (NRP1) expression by targeting the NRP1 3'-untranslated region. The results of the present study suggested that the LINC00887-miR-206-NRP1 axis served a critical role in regulating lung carcinoma cell proliferation, migration and invasion. In addition, xenograft tumor model experiments revealed that silencing LINC00887 suppressed lung carcinoma tumor growth of in vivo. In summary, our results suggest that LINC00887 may serve an oncogenic role in lung carcinoma by targeting the miR-206/NRP1 axis, providing a potential therapeutic target for patients with lung carcinoma.
\end{abstract}

Correspondence to: Dr Xiao-Ping Ren, The Second Department of Pulmonary and Critical Care Medicine, Shaanxi Provincial People's Hospital, 256 Youyi West Road, Xi'an, Shaanxi 710068, P.R. China E-mail:w94rxp@163.com

Key words: LINC00887, microRNA-206, NRP1, lung carcinoma, proliferation

\section{Introduction}

Lung carcinoma is one of the most common types of cancer and one of the leading causes of cancer-associated deaths worldwide $(1,2)$. In 2018, there were 2.1 million new cases and 1.8 million people died of lung cancer (3). The development and progression of lung cancer is a complicated process that may be associated with pleurisy or severe lung infections with bacteria and viruses or fungi, making lung cancer difficult to treat (4-6). Lung cancer can be divided into two categories, including non-small cell lung cancer (NSCLC) and small cell lung cancer (7). Although the treatment outcome for lung carcinoma have greatly improved due to advances in the technologies and treatment strategies, the prognosis of patients with lung carcinoma remains poor, since most patients are diagnosed at a late stage $(8,9)$. Alternative natural therapies, such as $\beta$-himachalene, apigenin, geranial and Dracocephalum kotschyi, have demonstrated anticancer properties, but with disadvantages such as cytotoxic effects (10-14). Therefore, research has focused on the understanding of the molecular mechanisms of lung carcinoma and identifying novel diagnostic biomarkers and therapeutic targets.

Epigenetic modifications by long non-coding RNAs (lncRNAs) and microRNAs (miRNAs) are crucial for the development and metastasis of lung cancer (15). lncRNAs are a group of RNAs $>200$ nucleotides in length involved in multiple biological processes including gene imprinting, histone modification, chromatin remodeling, transcriptional activation, transcriptional interference, nuclear transport, and cell cycle regulation. IncRNAs are also involved in development of various types of tumor (16-18). For example, NEAT1 (non-coding nuclear enriched abundant transcript 1) is upregulated in breast cancer, colorectal cancer and non-small cell lung cancer $(19,20)$. Small nucleolar RNA host gene 7 is upregulated in lung cancer tissues and cells and promotes the proliferation, migration and invasion of lung cancer cells by regulating Fas apoptotic inhibitory molecule 2 expression (21). miRNAs are a group of small non-coding RNAs that post-transcriptionally regulate gene expression and are also involved in tumor development and metastasis (22). Notably, lncRNAs have been reported to exert their functions as competing endogenous RNAs (ceRNAs) by sponging miRNAs (23-25). Previous studies have revealed various 
lncRNA-miRNA-mRNA interaction networks in lung carcinoma (26-28). Cong et al (26) have demonstrated that lncRNA LINC00665 functions as a ceRNA to sponge miR-98, which regulates ERK signaling, and promotes the development of lung cancer. IncRNA PVT1 has been reported to competitively bind miR-424-5p, which is involved in regulating the coactivator-associated arginine methyltransferase 1 in NSCLC (29). Furthermore, lncRNAs can exert oncogenic roles, as well as function as tumor inhibitors. For example, lncRNA GACAT3 expression is decreased in NSCLC, and high expression levels of lncRNA GACAT3 inhibit the invasion and metastasis of NSCLC (30). Another study has demonstrated that lncRNA BX357664 suppresses NSCLC development by inhibiting cell proliferation and invasion (31). However, the roles of lncRNA-miRNA-mRNA networks in lung carcinoma remain unclear. Previously, LINC00887 has been identified to accelerate the malignant transformation ability of NSCLC cells (32). Using high-throughput nascent RNA capture sequencing, another study has identified LINC00887 as a highly expressed lncRNA in lung adenocarcinoma and squamous cell carcinoma (33). However, the detailed underlying mechanisms require further clarification.

The present study aimed to investigate the role of the LINC00887/miR-206/NRP1 axis in the development of lung cancer. LINC00887 functioned as the sponge of miR-206 to upregulate NRP1 expression. A decrease in LINC00887 may serve as a prognostic and diagnostic marker and also be used as a novel therapeutic target for patients with lung cancer.

\section{Materials and methods}

Clinical specimens. Lung carcinoma tissues and adjacent normal tissues ( $>5 \mathrm{~cm}$ from tumor) were obtained from 40 patients (age range, $35-70$ years; mean age, $63 \pm 7.83$ years) with lung cancer who underwent surgical resection at Shaanxi Provincial People's Hospital (Xi'an, China) between March 2017 and December 2018. Two pathologists evaluated all specimens according to the World Health Organization guidelines and the pTNM Union for International Cancer Control pathological staging criteria (34). Inclusion criteria were: i) Primary lung cancer diagnosed by pathological examination; and ii) No local or systemic treatments were administered before surgery. All tissues were frozen in liquid nitrogen until RNA isolation. Written consent was obtained from all patients. The present study was approved by the Ethics Committee of Shaanxi Provincial People's Hospital (approval number, XJYYLL-2019287).

Cell culture and transfection. Three lung carcinoma cell lines, namely the adenocarcinoma A549 cell line and the large cell carcinoma NCI-H1299 and NCI-H460 cell lines, were obtained from the American Type Culture Collection. The normal human bronchial epithelial BEAS-2B cell line was obtained from the Chinese Cell Bank of the Chinese Academy of Sciences. The cells were cultured in RPMI-1640 medium (Gibco; Thermo Fisher Scientific Inc.) with 10\% FBS (Hyclone; GE Healthcare Life Sciences), $1 \%$ penicillin and streptomycin at $37^{\circ} \mathrm{C}$ with $5 \% \mathrm{CO}_{2}$. Mycoplasma detection was negative in all cell lines.
Table I. Sequence of si-LINC00887, miR-206 mimics, miR-inhibitors and their negative controls.

\begin{tabular}{ll}
\hline Oligonucleotides & \multicolumn{1}{c}{ Sequence $\left(5^{\prime} \rightarrow 3^{\prime}\right)$} \\
\hline si-NC & GGCCTTTGCGTCACGCCTTAG \\
si-LINC00887 1\# & GGCCTTTGCAGTTATTAGGAA \\
si-LINC00887 2\# & CCTGTTCTCTCTGGTTCTC \\
si-LINC00887 3\# & GTCCCTGTTCTCTCTGGTT \\
mimics-NC & UUGUACUACACAAAAGUACUG \\
miR-206 mimics & UGGAAUGUAAGGAAGUGUGUGG \\
inhibitor NC & CAGUACUUUUGUGUAGUACAA \\
miR-206 inhibitor & CCACACACUUCCUUACAUUCCA
\end{tabular}

miR, microRNA; siRNA, small interfering RNA; NC, negative control.

BEAS-2B, A549 or NCI-H460 cells were seeded in 6- or 96-well plates. When the confluency reached $60-70 \%$, the medium was changed to serum-free RPMI-1640, and transfection with small interfering (si)RNAs targeting LINC00887 or a control siRNA (si-Con). MiR-206 mimics, miR-206 inhibitors and their negative controls were obtained from Guangzhou RiboBio Co., Ltd. LINC00887 was overexpressed using the expression plasmid pcDNA3.1(+) (Invitrogen; Thermo Fisher Scientific Inc.). Empty vectors without LINC00887 cDNA were used as negative controls. LINC00887 siRNA (si-LINC00887, and negative control (si-NC) were purchased from Shanghai GenePharma Co. Ltd. Cells were transfected with LINC00887 siRNA, miR-206 mimics, miR-206 inhibitors and their negative controls at $50 \mathrm{nM}$ concentration. All transfections were performed using Lipofectamine ${ }^{\circledR} 3000$ (Invitrogen; Thermo Fisher Scientific, Inc.) according to the manufacturer's protocol. The sequences of all mimics and inhibitors and their negative controls are presented in the Table I. Cells were harvested $72 \mathrm{~h}$ after transfection for further experiments.

Reverse transcription-quantitative PCR (RT-qPCR). Total RNA from tissues and cell lines was isolated using TRIzol ${ }^{\circledR}$ reagent (Invitrogen; Thermo Fisher Scientific, Inc.). cDNA was synthesized using the PrimeScript RT reagent kit (Takara Bio, Inc.). qPCR was performed from cDNA using the SYBR ${ }^{\circledR}$ Green PrimeScript ${ }^{\mathrm{TM}}$ PLUS RT-PCR kit (Takara Bio, Inc.). The reaction conditions were $95^{\circ} \mathrm{C}$ for $30 \mathrm{sec}, 60^{\circ} \mathrm{C}$ for $40 \mathrm{sec}$ (40 cycles), and a final extension step at $72^{\circ} \mathrm{C}$ for $10 \mathrm{~min}$. Small RNA-rich samples were isolated from cells using TRIzol ${ }^{\circledR}$ reagent or the mirVana miRNA Isolation kit (Thermo Fisher Scientific, Inc.). U6 or GAPDH was used as an endogenous control. The relative expression levels were analyzed using the $2^{-\Delta \Delta \mathrm{Cq}}$ method (35). The primers used are listed in Table II.

Cell proliferation assays. A549 or NCI-H460 cells $\left(3 \times 10^{3}\right.$ cells/well) were seeded in 96-well plates. After transfection with si-NC or si-LINc00887, cell proliferation was evaluated using a Cell Counting Kit-8 (CCK-8) assay (Dojindo Molecular Technologies, Inc.) according to the manufacturer's instructions. Cells were cultured for 0,24 , 
Table II. Primers used in the present study.

\begin{tabular}{lll}
\hline Gene & Forward $\left(5^{\prime} \rightarrow 3^{\prime}\right)$ & Reverse $\left(5^{\prime} \rightarrow 3^{\prime}\right)$ \\
\hline miR-206 & GCGTCTGGAATGTAAGGAAGTG & GTGCAGGGTCCGAGGT \\
U6 & TTGGTCTGATCTGGCACATATAC & AAAAATATGGAGCGCTTCACG \\
NRP1 & ATGCGAATGGCTGATTCAGG & TCCATCGAAGACTTCCACGTAG \\
LINC00887 & TCCTGCTTGGCAGGTAACAG & AACGATGCCTCAGTCGAAGG \\
& TGTCACCAACTGGGACGATA & GGGGTGTTGAAGGTCTCAAA \\
\hline
\end{tabular}

NRP1, neuropilin 1; miR, microRNA.

48 or $96 \mathrm{~h}$ at $37^{\circ} \mathrm{C}$ and incubated with $10 \mu \mathrm{lCCK}-8$ reagent per well at $37^{\circ} \mathrm{C}$ for $1 \mathrm{~h}$. The absorbance was measured at $450 \mathrm{~nm}$ using an Exl 800 microplate reader (BioTek China). The 5-ethynyl-2'-deoxyuridine (EdU) staining assay was performed to determine DNA synthesis in proliferating cells using an EdU assay kit (Invitrogen; Thermo Fisher Scientific, Inc.). After transfection with si-NC or si-LINC00887, A549 or NCI-H460 cells were cultured at $37^{\circ} \mathrm{C}$ for $48 \mathrm{~h}$, fixed with $4 \%$ paraformaldehyde at room temperature for $10 \mathrm{~min}$ and permeabilized with $0.3 \%$ Triton X-100 at room temperature for $10 \mathrm{~min}$. Subsequently, cells were incubated with $10 \mu \mathrm{M}$ EdU for $2 \mathrm{~h}$ at $37^{\circ} \mathrm{C}$, and cell nuclei were stained with DAPI $(5 \mu \mathrm{g} / \mathrm{ml})$ at room temperature for $10 \mathrm{~min}$. The number of EdU-positive cells was counted under a light microscope in five random fields (magnification, x100; Olympus Corporation). All assays were independently performed in triplicate.

Wound healing assay. After transfection with si-NC or

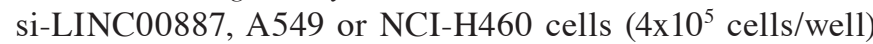
were seeded in 6 -well plates and cultured at $37^{\circ} \mathrm{C}$ until confluent. The wound was created by scratching the cell layer with a sterile pipette tip. The floating cells were washed away using PBS. The streaked cells were cultured in serum-free RPMI-640 medium at $37^{\circ} \mathrm{C}$ for $48 \mathrm{~h}$. An inverted optical microscope (Olympus Corporation) was used to monitor the closure of the wound at 0 and $48 \mathrm{~h}$ at $\times 50$ magnification. The gap distance was quantitatively evaluated using ImageJ software (version 1.49; National Institutes of Health).

Cell migration and invasion assays. For invasion assays, 24-well Transwell chambers $(8.0 \mu \mathrm{m}$ pore size, Costar; Corning, Inc.) with Matrigel-precoated membranes were used. A total of $1 \times 10^{5}$ A549 or NCI-H460 cells in $100 \mu 1$ FBS-free RPMI-1640 were added to the upper chambers, while $500 \mu \mathrm{l}$ RPMI-1640 medium with 10\% FBS was added to the bottom chambers. After $48 \mathrm{~h}$, the non-invaded cells on the upper side of the membrane in the chamber were removed by swabs, and the invading cells in the lower side of the chamber were stained with $0.1 \%$ crystal violet for $20 \mathrm{~min}$ at room temperature. The cells were observed and counted under a light microscope (magnification, x200; Olympus Corporation). For migration detection, the Matrigel was not used and all other steps were the same as the cell invasion assay.

Western blotting. A549 or NCI-H460 cells were lysed using RIPA buffer (Sigma-Aldrich; Merck KGaA) with $1 \mathrm{mM}$ phenylmethylsulphonyl fluoride. The concentration of obtained total protein was quantified using a BCA protein assay kit (Thermo Fisher Scientific, Inc.). Equal amounts $(25 \mu \mathrm{g})$ of proteins were loaded and separated via 10\% SDS-PAGE and electro-transferred to a PVDF membrane (EMD Millipore). After blocking with 5\% bovine serum albumin (Beyotime Institute of Biotechnology) at room temperature for $1 \mathrm{~h}$, the membrane was incubated with anti-neuropilin 1 (NRP1) (1:2,000; cat. no. ab81321; Abcam) and anti- $\beta$-actin (1:5,000; ab179467; Abcam) primary antibodies at $4^{\circ} \mathrm{C}$ overnight. After washing three times with TBST (5 min per wash), the members were subsequently incubated with an HRP-labelled goat anti-rabbit secondary antibody (ab6721; 1:10,000; Abcam) at room temperature for $1 \mathrm{~h}$. The immunolabelling was visualized using an ECL system (EMD Millipore) according to the manufacturer's protocol. All assays were performed independently in triplicate and the densitometric analysis was performed using ImageJ (version 1.49; National Institutes of Health).

Dual-luciferase reporter assay. The reporter plasmid containing 3'UTR of LINC00887 or NRP1 with wild (Wt LINC00887 or Wt NRP1) or mutant (Mut LINC00887 or Mut NRP1) miR-206 binding sites were constructed by Guangzhou RiboBio Co. Ltd. For the reporter assay, lung cancer cells or 293T cells in 24-well plates and co-transfected with the reporter plasmid and miR-206 mimic or NC using Lipofectamine ${ }^{\circledR}$ 2000 (Invitrogen, Thermo Fisher Scientific, Inc.). Cells were harvested $48 \mathrm{~h}$ later and assayed with a luciferase reporter assay system (Promega Corporation). The relative luciferase activity was normalized to Renilla luciferase activity.

Tumor xenograft model. BALB/c nude mice (age, 8 weeks; weight, 21-25 g) were obtained from Beijing Vital River Laboratory Animal Technology Co., Ltd., and housed at a room temperature of $25^{\circ} \mathrm{C}$ with a $12 \mathrm{~h}$ light/dark cycle. The mice were maintained in an individually ventilated cage system under specific pathogen-free conditions (temperature; $25^{\circ} \mathrm{C}$; humidity, 55\%) with free access to food and water. Then the posterior flank of 6-week-old male BALB/c nude mice $(n=10)$ were subcutaneously injected with NCI-H460 $\left(4 \times 10^{6}\right)$ cells transfected with si-NRP1 or si-negative control (NC). Tumor volumes were examined every 4 days. After 17 days, the mice were euthanized by $\mathrm{CO}_{2}$ inhalation $\left(\mathrm{CO}_{2}\right.$ flow rate, $20 \%$ of cage volume) and tumor tissues were dissected, photographed and weighed. The expression levels of miR-206 in tumor tissues 

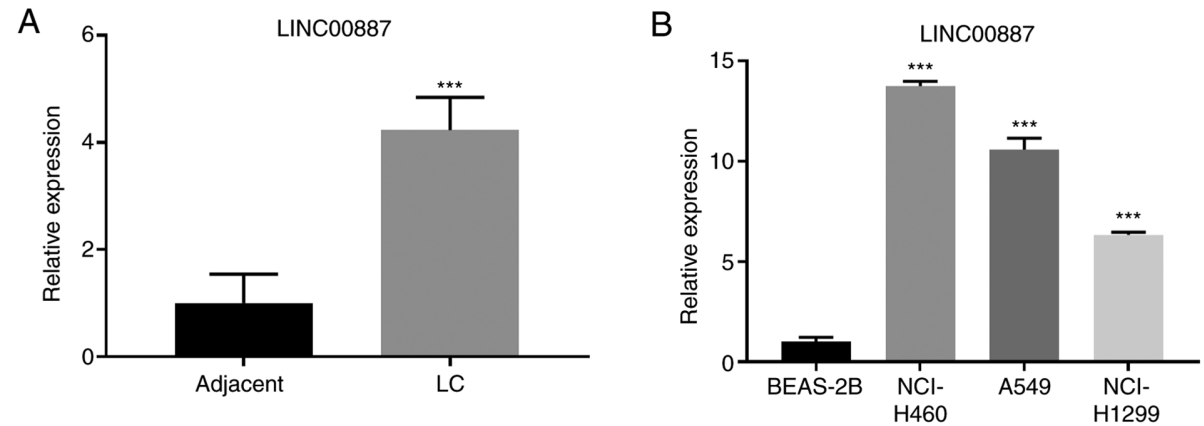

Figure 1. LINC00887 is upregulated in LC tissues and cell lines. (A) Expression levels of LINC00887 in LC tissues compared with adjacent normal tissues analyzed via RT-qPCR. (B) Expression levels of LINC00887 in human LC cell lines NCI-H460, A549 and NCI-H1299, and the normal human bronchial epithelial cell line BEAS-2B were analyzed by reverse transcription-quantitative PCR. Data are presented as the mean $\pm \mathrm{SD}$. ${ }^{* * *} \mathrm{P}<0.001 \mathrm{vs}$. adjacent or BEAS-2B. LC, lung carcinoma.

Table III. Association between LINC00887 and clinical features of patients.

\begin{tabular}{lccc}
\hline & \multicolumn{2}{c}{ LINC00887 expression } & \\
\cline { 2 - 3 } Characteristics & Low (n=20) & High (n=20) & P-value \\
\hline Age, years & & & \\
$\quad \leq 65$ & 11 & 10 & 0.752 \\
$>65$ & & 10 & \\
Sex & 12 & 13 & 0.744 \\
Male & 8 & 7 & \\
Female & & & \\
TNM stage & 15 & 7 & 0.011 \\
I+II & 5 & 13 & \\
III+IV & & & \\
Lymph node metastasis & 10 & 3 & 0.018 \\
Negative & 10 & 17 & \\
Positive & & & \\
\hline
\end{tabular}

Low or high expression of LINC00887 was determined by using median expression as a cut-off. P-value was calculated using the $\chi^{2}$ test. TNM, tumor-node-metastasis.

were detected by RT-qPCR as aforementioned. The protein levels of NRP1 in tumor tissues were measured by western blotting as aforementioned. The murine experiments were conducted in July 2017. The animal experiment was performed in compliance with the authenticated animal protocols of the Ethical Committee of Animal Welfare of Shaanxi Provincial People's Hospital (approval. No. IACUC-20190116).

Target prediction. Potential target miRNAs of LINC00887 were predicted using LncBase V2(http://carolina.imis.athena-innovation.gr/diana_tools/web/index.php? $r=1$ ncbasev2/index). The target genes of miR-206 were predicted using the bioinformatics algorithms: TargetScanV7.2 (http://www.targetscan. org/vert_72/).

Statistical analysis. Statistical analyses were performed using GraphPad Prism 7.0 (GraphPad Software, Inc.). Data are presented as the mean \pm SD for three independent experiments. The differences between two groups were analyzed by unpaired Student's t-test, and one-way ANOVA followed by the Tukey's post hoc test was performed to analyze the differences among more than 2 groups. Pearson's correlation analysis was performed to analyze the correlation between LINC00887 and miR-206 expression as well as the clinical variables. $\mathrm{P}<0.05$ was considered to indicate a statistically significant difference.

\section{Results}

LINC00887 is upregulated in lung carcinoma tissues and cell lines. RT-qPCR was performed to analyze the expression levels of LINC00887 in the collected 40 pairs of lung carcinoma and adjacent normal tissues. As presented in Fig. 1A, LINC00887 expression levels were significantly upregulated in lung carcinoma tissues compared with those in adjacent normal tissues $(\mathrm{P}<0.001)$. To assess the association of LINC00887 expression with clinicopathologic characteristics, the expression levels of LINC00887 were categorized as low $(n=20)$ or high $(n=20)$ in relation to the median value (cut-off, 2.12). High LINC00887 expression was significantly associated with advanced TNM stage and lymph node metastasis (Table III). Additionally, LINC00887 expression levels were significantly higher in three lung cancer cell lines (NCI-H460, A549 and NCI-H1299) compared with those in the normal human bronchial epithelium BEAS-2B cell line (Fig. 1B). NCI-H460 and A549, which exhibited high expression levels of LINC00887, were used for subsequent in vitro assays.

LINC00887 knockdown suppresses proliferation, migration and invasion of lung carcinoma cells in vitro. To investigate the function of LINC00887, the expression of LINC00887 was knocked down using siRNAs. All three siRNAs mentioned in Table I significantly silenced LINC00887 expression compared with that in the si-Con group, with si-LINC00887-2 exhibiting the strongest knockdown efficiency (Fig. 2A). Therefore, subsequent experiments were performed using si-LINC00887-2. The CCK-8 assay demonstrated that cell proliferation was significantly decreased in A549 and NCI-H460 lung carcinoma cells after si-LINC00887 transfection compared with that in cells transfected with si-Con $(\mathrm{P}<0.01$; Fig. $2 \mathrm{~B}$ and $\mathrm{C})$. 

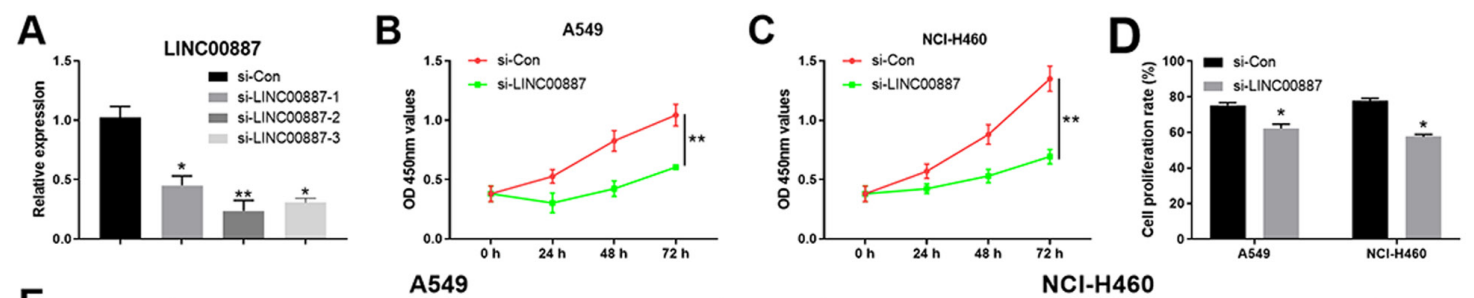

E
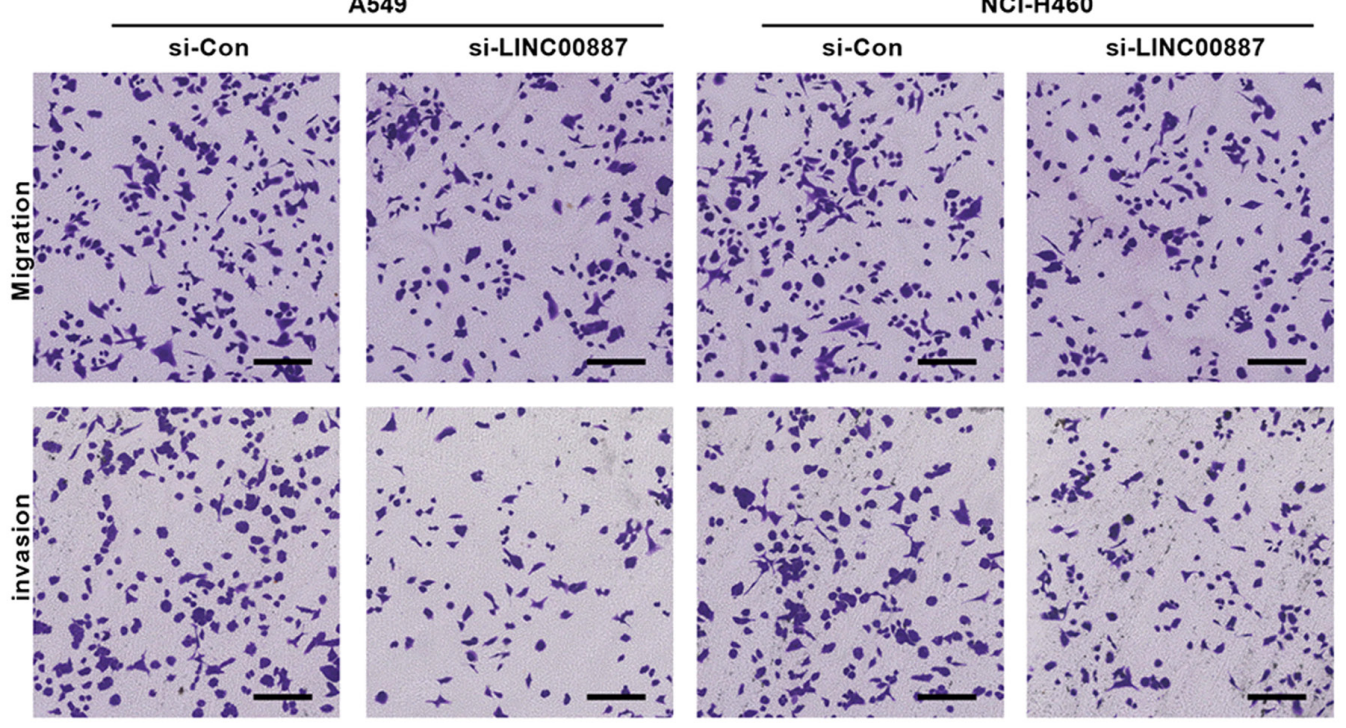

$\mathbf{F}$

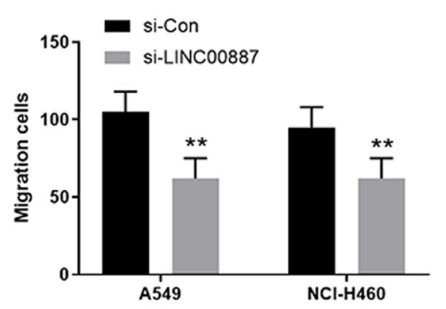

H
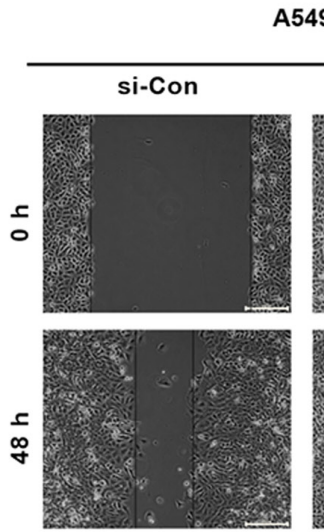

A549
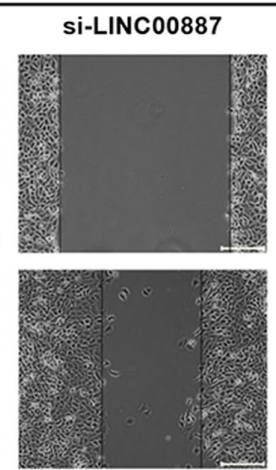

G

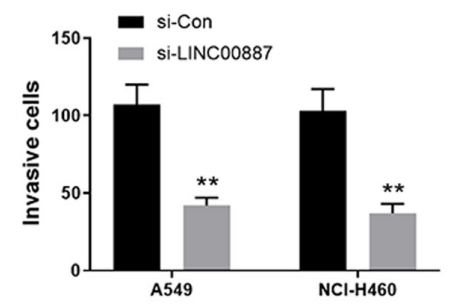

$\mathrm{NCl}-\mathrm{H} 460$

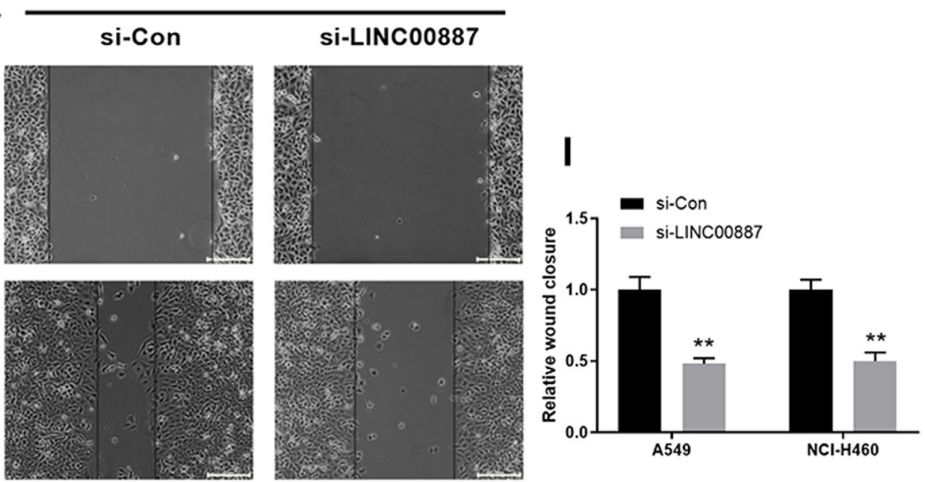

Figure 2. LINC00887 knockdown suppresses the proliferation, migration and invasion of lung carcinoma cells in vitro. (A) NCI-H460 cells were transfected with si-Con or three different plasmids of si-LINC00887. The knockdown efficiency was analyzed by reverse transcription-quantitative PCR. (B-D) The cell proliferation of (B) A549 and (C) NCI-H460 cells transfected with si-Con or si-LINC00887 was assessed using the Cell Counting Kit-8 assay at different time points or (D) by EdU and DAPI staining. (E-G) The migratory and invasive capabilities of A549 and NCI-H460 lung carcinoma cells transfected with si-Con or si-LINC00887 were analyzed using Transwell assays. Scale bar, $200 \mu \mathrm{m}$. (H and I) Wound healing assay was performed to determine the effects of LINC00887 knockdown on A549 and NCI-H460 cells. Scale bar, $200 \mu \mathrm{m}$. Data are presented as the mean \pm SD. ${ }^{*} \mathrm{P}<0.05 ;{ }^{* *} \mathrm{P}<0.01$ vs. si-Con. si, small interfering RNA; Con, control; OD, optical density; EdU, 5'-ethynyl-2'-deoxyuridine.

Consistently, EdU and DAPI double staining confirmed that LINC00887 knockdown significantly inhibited the proliferation of A549 and NCI-H460 cells $(\mathrm{P}<0.05$; Figs. 2D and S1). Furthermore, Transwell assays revealed that silencing LINC00887 significantly inhibited the migratory and invasive capabilities of A549 and NCI-H460 lung carcinoma cells ( $\mathrm{P}<0.01$; Fig. $2 \mathrm{E}-\mathrm{G})$. In addition, wound healing assays demonstrated that LINC00887 knockdown significantly decreased the relative wound closure in A549 and NCI-H460 cells ( $\mathrm{P}<0.01$; Fig. $2 \mathrm{H}$ and $\mathrm{I})$. To further 
A

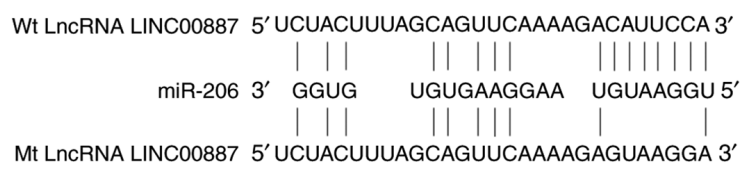

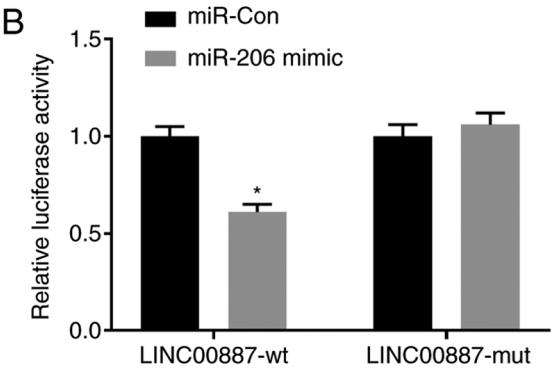

C

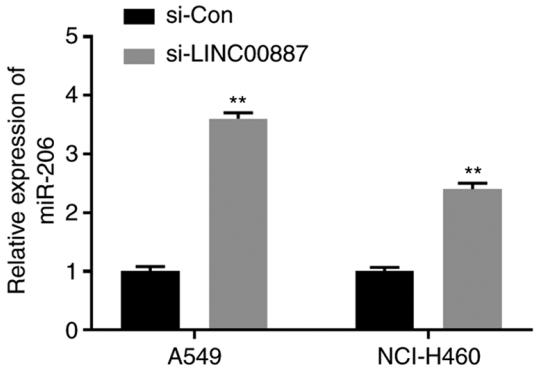

$\mathrm{E}$

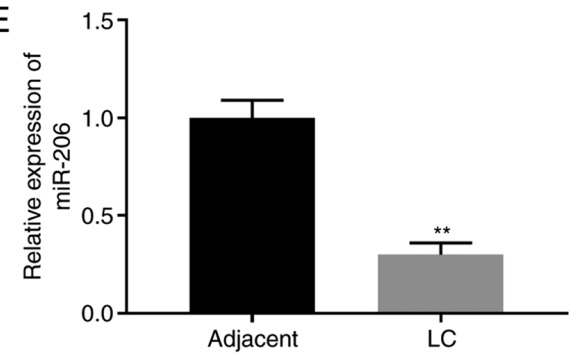

D

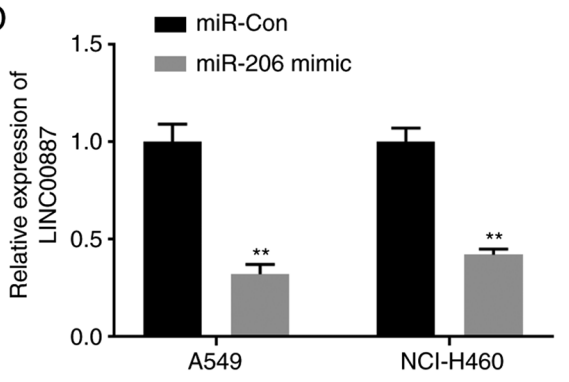

$\mathrm{F}$

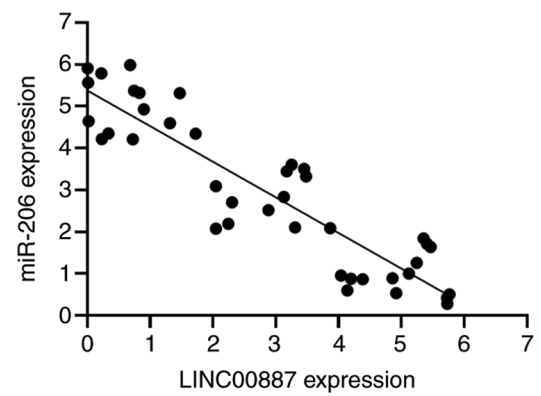

Figure 3. LINC00887 directly interacts with miR-206. (A) Putative binding site between lncRNA LINC00887 and miR-206 revealed by the DIANA-LncBase. (B) 293 cells were transfected with luciferase reporter vectors containing lncRNA LINC00887 WT or mutant sequences (pmirGLO-LINC00887-wt or pmirGLO-LINC00887-mut, respectively), in the presence of miR-206 mimic or miR-Con. Relative luciferase activity was analyzed $72 \mathrm{~h}$ later. (C) Expression levels of miR-206 in LC A549 and NCI-H460 cells transfected with si-Con or si-LINC00887 were analyzed via RT-qPCR $72 \mathrm{~h}$ post transfection. (D) Expression levels of LINC00887 in LC A549 and NCI-H460 cells transfected with miR-Con or miR-206 mimic were analyzed by RT-qPCR 72 h post transfection. (E) Expression levels of miR-206 in LC tissues and adjacent normal tissues were analyzed via RT-qPCR. (F) Pearson correlation analysis between miR-206 expression and LINC00887 expression in LC tissues. Data are presented as the mean $\pm \mathrm{SD}$. ${ }^{*} \mathrm{P}<0.05 ;{ }^{* * *} \mathrm{P}<0.01$ vs. miR-Con, si-Con or adjacent tissues. RT-qPCR, reverse transcription-quantitative PCR; LC, lung carcinoma; miR, microRNA; Con, control; si, small interfering RNA; wt, wild-type; mt, mutant.

validate the function of LINC00887, LINC00887 was overexpressed in normal human lung epithelial BEAS-2B cells (Fig. S2A). LINC00887 overexpression did not alter cell proliferation, migration and invasion in normal BEAS-2B cells (Fig. S2B-F). In summary, the present results suggested that LINC00887 knockdown suppressed the proliferation, migration and invasion of lung carcinoma cells in vitro.

LINC00887 directly interacts with miR-206. Multiple studies have demonstrated that lncRNAs can exert their functions as competing endogenous RNAs (ceRNAs) by competitively binding miRNAs involved in regulating target gene expression $(36,37)$. However, whether LINC00887 has a similar function in lung carcinoma remains unknown. Using the bioinformatics DIANA tool lncbase V2 (38), miR-206 was identified to have putative binding sites with LINC00887 (Fig. 3A). To verify whether LINC00887 directly interacted with miR-206, Dual-Luciferase reporter assays were performed, and the results revealed that the miR-206 mimic significantly inhibited the luciferase activity of the LINC00887-wt reporter, but not that of the LINC00887-mut reporter (Fig. 3B). In addition, the regulation between miR-206 and LINC00887 was further examined; as presented in Fig. 3C, LINC00887 knockdown significantly upregulated miR-206 expression, whereas miR-206 overexpression using the miR-206 mimic significantly downregulated LINC00887 expression in A549 and NCI-H460 lung carcinoma cells (Fig. 3D). Notably, significantly lower levels of miR-206 were detected in lung carcinoma tissues compared with those in adjacent normal tissues (Fig. 3E). Pearson's correlation analysis revealed that miR-206 expression was negatively correlated with LINC00887 expression ( $\mathrm{P}<0.001$; Fig. 3F).

LINC00887 regulates lung carcinoma cell proliferation, migration and invasion via miR-206. To further investigate the functional association between LINC00887 and miR-206, and test whether LINC00887 exerts its function via miR-206, a miR-206 inhibitor was used to downregulate miR-206 expression in lung carcinoma A549 and NCI-H460 cells (Fig. 4A). As LINC00887 knockdown enhanced miR-206 expression (Fig. 3C), A549 and NCI-H460 cells transfected with si-LINC00887 were further transfected with the miR-206 inhibitor or inhibitor-NC. As presented in Figs. 4B-D and S3, 

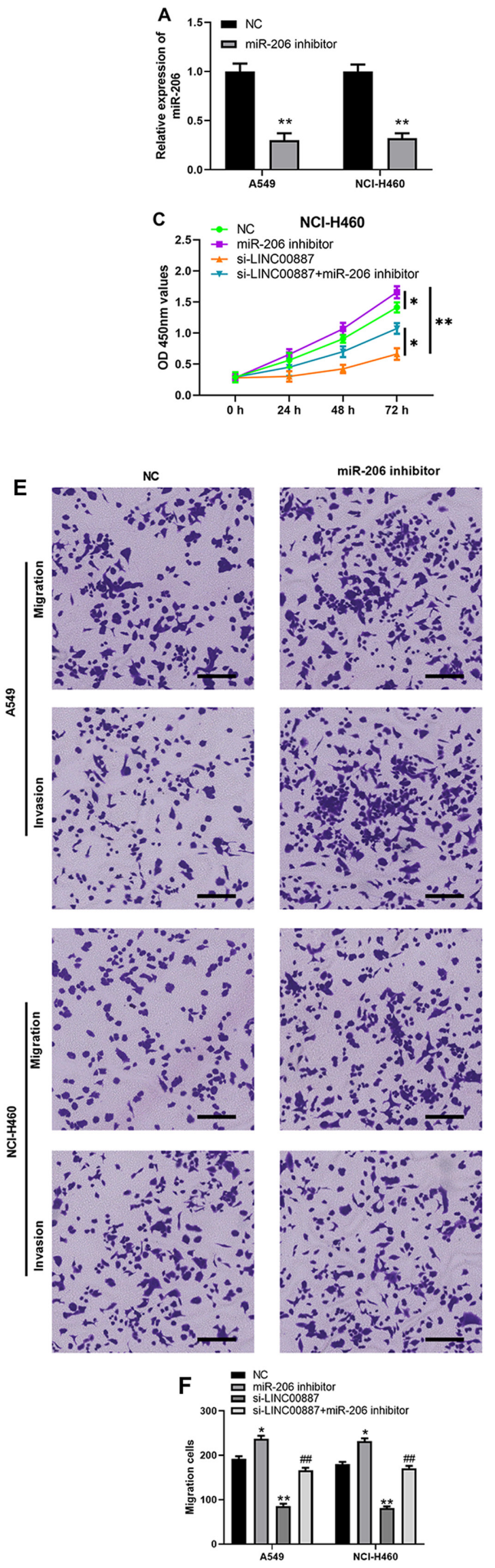
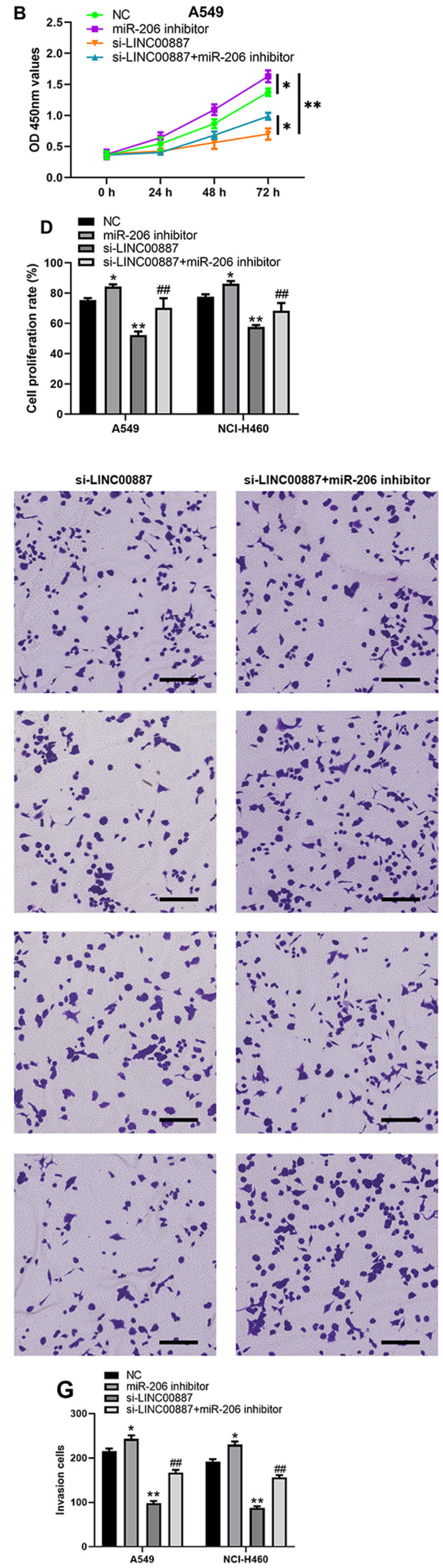

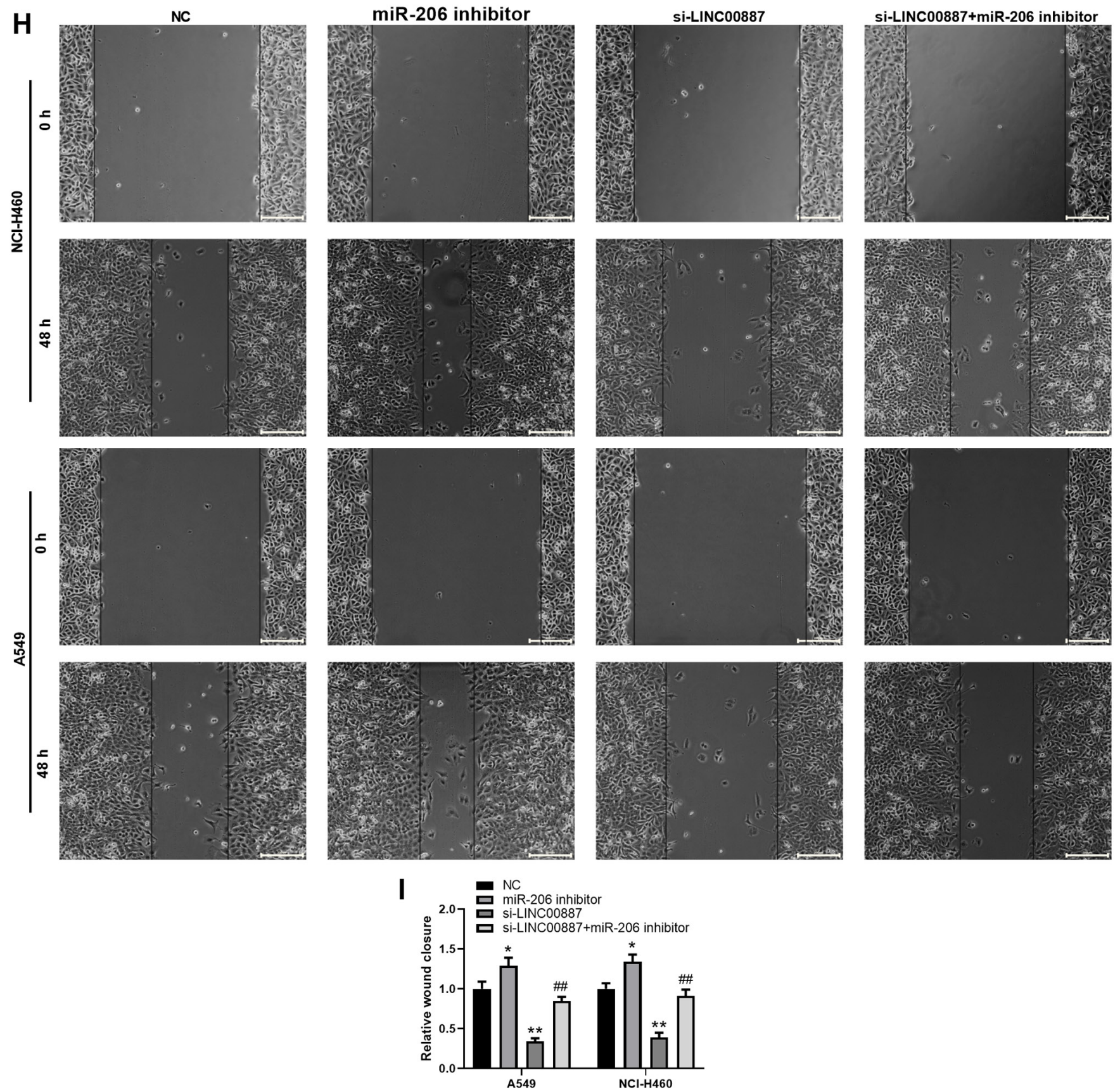

Figure 4. LINC00887 regulates lung carcinoma cell proliferation, migration and invasion via miR-206. (A) Expression levels of miR-206 in lung carcinoma A549 and NCI-H460 cells transfected with inhibitor-NC or miR-206 inhibitor were examined by reverse transcription-quantitative PCR. (B and C) Lung carcinoma A549 or NCI-H460 cells were co-transfected with si-LINC00887 and inhibitor-NC or miR-206 inhibitor. (B and C) Cell proliferation was analyzed using the Cell Counting Kit-8 assay in (B) A549 and (C) NCI-H460 cells at the indicated time points. (D) Cell proliferation was analyzed by EdU and DAPI staining $72 \mathrm{~h}$ post transfection. (E) Transwell assays were used to analyze (F) cell migration and (G) invasion. Scale bar, $200 \mu \mathrm{m}$. (H and I) Relative wound closure was examined by wound healing assay. Scale bar, $200 \mu \mathrm{m}$. Data are presented as the mean $\pm \mathrm{SD}$. ${ }^{*} \mathrm{P}<0.05 ;{ }^{* *} \mathrm{P}<0.01 \mathrm{vs}$. NC. ${ }^{\# \#} \mathrm{P}<0.01 \mathrm{vs}$. $\mathrm{NC}$. NC, inhibitor-NC; miR, microRNA; si, small interfering RNA; OD, optical density; EdU, 5'-ethynyl-2'-deoxyuridine.

the results of the CCK-8 and EdU/DAPI staining assays demonstrated that LINC00887 knockdown significantly inhibited cell proliferation, whereas miR-206 inhibitor ameliorated the inhibition of cell proliferation induced by LINC00887 knockdown in lung carcinoma A549 and NCI-H460 cells. Consistently, as demonstrated by Transwell and wound healing assays, silencing LINC00887 significantly inhibited cell migration or invasion, whereas miR-206 inhibitor ameliorated the inhibition of cell migration or invasion induced by LINC00887 knockdown in lung carcinoma A549 and NCI-H460 cells (Fig. 4E-I).
miR-206 regulates NRP1 expression by targeting NRP1 3 '-UTR. To determine the target of miR-206 in lung carcinoma, bioinformatics prediction was performed using TargetScan, which revealed that miR-206 targeted the 3'-UTR of NRP1 with 17 complementary binding sites (Fig. 5A). To validate the prediction, Dual-Luciferase reporter assay was performed, and the results demonstrated that the relative luciferase activities in 293T cells transfected with the NRP1-wt reporter vector, but not with NRP1-mut, were inhibited by co-transfection with the miR-206 mimic (Fig. 5B). Furthermore, miR-206 
A

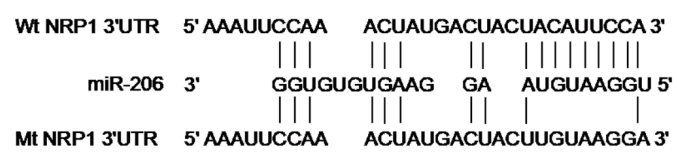

C

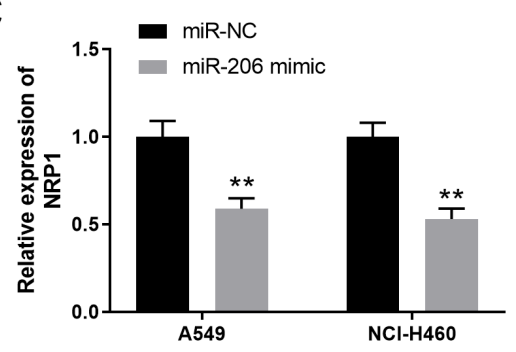

$\mathbf{E}$

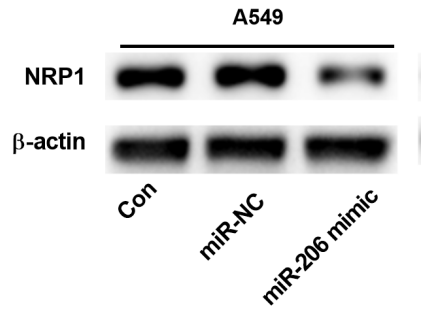

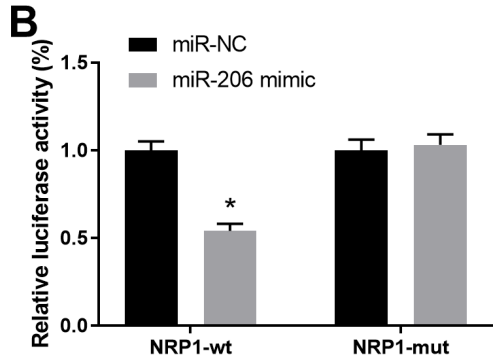

D

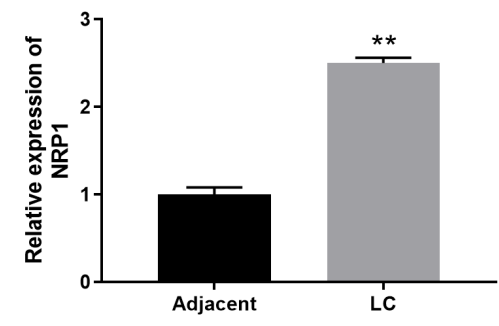

$\mathbf{F}$ con

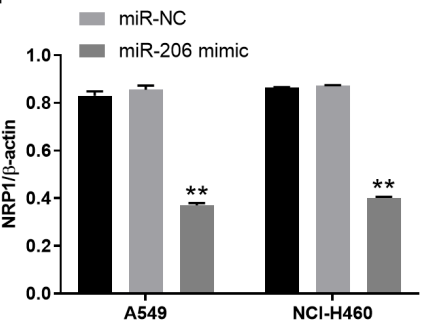

Figure 5. miR-206 regulates NRP1 expression by targeting the NRP1 3'-UTR. (A) Bioinformatics analysis revealed the predicted binding sites between NRP1 3'-UTR and miR-206. (B) Relative luciferase activity in 293 cells transfected with luciferase reporter vectors containing the NRP1 3'-UTR WT sequence (NRP1-wt) or mutated sequence (NRP1-mut), in the presence of miR-Con or miR-206 mimic. (C) mRNA expression levels of NRP1 in A549 and NCI-H460 cells transfected with miR-Con or miR-206 mimic were detected by RT-qPCR. (D) mRNA expression levels of NRP1 in LC tissues or in adjacent normal tissues were analyzed by RT-qPCR. (E and F) Protein expression levels of NRP1 in A549 and NCI-H460 cells transfected with miR-NC or miR-206 mimic were detected via western blotting. Data are presented as the mean \pm SD. ${ }^{*} \mathrm{P}<0.05 ;{ }^{* *} \mathrm{P}<0.01$ vs. miR-Con or adjacent tissues. NRP1, neuropilin $1 ; 3$ '-UTR, 3'-untranslated region; wt, wild-type; mut, mutant; RT-qPCR, reverse transcription-quantitative PCR; LC, lung carcinoma; miR, microRNA; Con, control.

overexpression significantly downregulated both the mRNA and protein levels of NRP1 in lung carcinoma A549 and NCI-H460 cells (Figs. 5C, E and F, and S5). In addition, significantly higher expression levels of NRP1 were detected in lung carcinoma tissues compared with those in the adjacent normal control tissues (Fig. 5D).

LINC00887-miR-206-NRP1 interaction network regulates lung carcinoma cell proliferation, migration and invasion. To further validate the function of the LINC00887-miR-206-NRP1 interaction network, lung carcinoma A549 and NCI-H460 cells were transfected with si-LINC00887, miR-206 mimic, si-NRP1 or the si-NC. CCK-8 assays revealed that compared with the NC, transfection with si-LINC00887, miR-206 mimic or si-NRP1 significantly inhibited A549 and NCI-H460 cell proliferation (Figs. 6A and B, and S5). The effect of si-LINC00887, miR-206 mimic on cell proliferation was further confirmed using EdU/DAPI staining (Figs. 6C and S4). Transwell assays demonstrated that LINC00887 knockdown, miR-206 overexpression or NRP1 silencing significantly inhibited migration and invasion of A549 and NCI-H460 cells (Fig. 6D-F). In addition, wound healing assays revealed that si-LINC00887, miR-206 mimic significantly inhibited the relative migration distance of A549 and NCI-H460 (Fig. 6G and H). NRP1 protein levels in A549 and NCI-H460 cells transfected with si-LINC00887, the miR-206 mimic, si-NRP1 or the NC were further analyzed. Compared with the NC group, LINC00887 knockdown, miR-206 overexpression or NRP1 silencing significantly inhibited NRP1 protein expression, with si-NRP1 transfection exhibiting the lowest expression levels of NRP1 protein among all groups (Fig. 6I and J).

LINC00887 knockdown inhibits lung carcinoma tumor growth in vivo. To investigate the function of LINC00887 on tumor growth in vivo, a xenograft tumor model was established using NCI-H460 cells transfected with si-NC or si-LINC00887 (Fig. 7A). The tumor volume was measured every 4 days after implantation and mice were euthanized on day 17 (Fig. 7B). Compared with the si-NC group, the tumor growth was significantly inhibited in the si-LINC00887 group (Fig. 7B), with significantly lower xenograft tumor sizes and weights (Fig. 7A-D). Additionally, LINC00887 
A

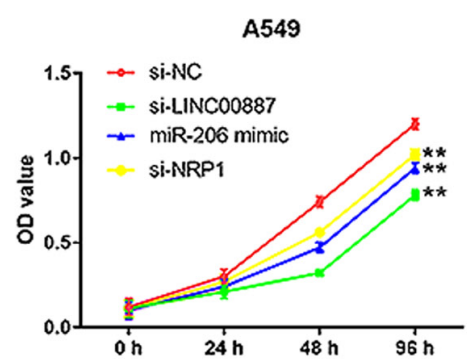

B

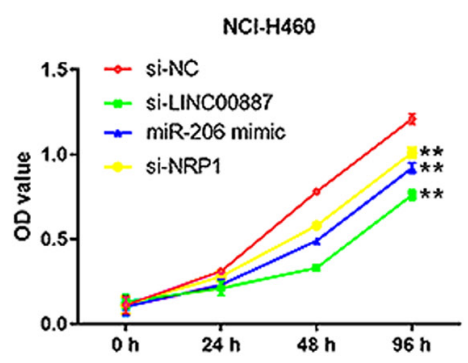

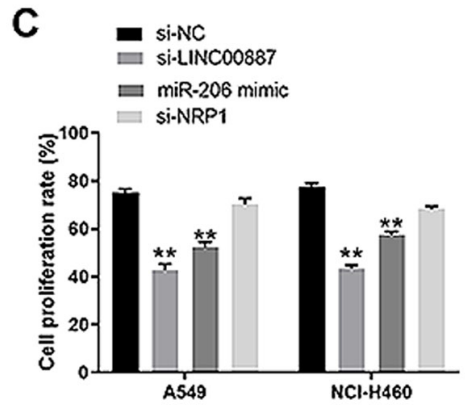

D Si-NC Si-LINC00887

miR-206 mimic

si-NRP1

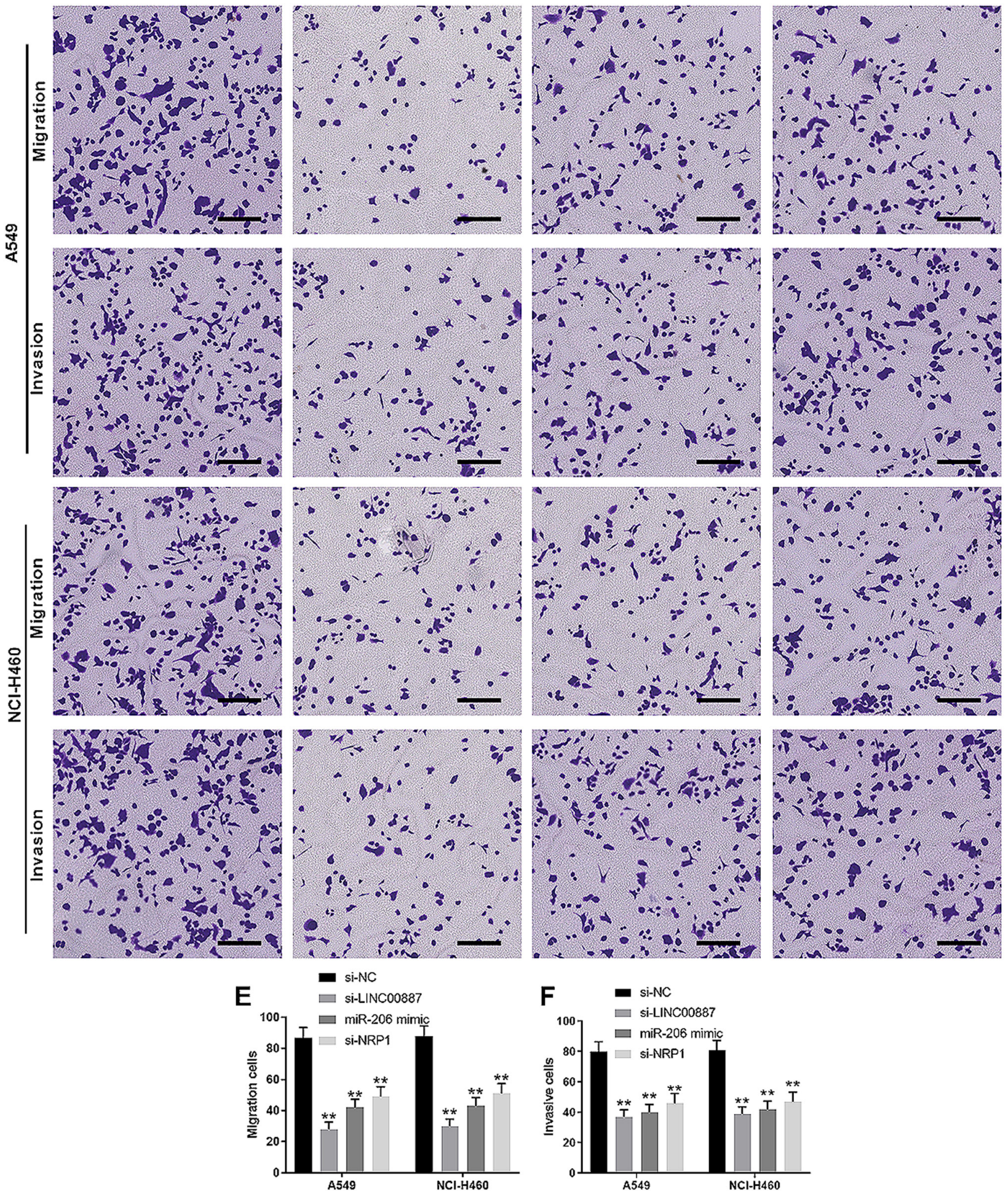

Figure 6. Continued. 
G
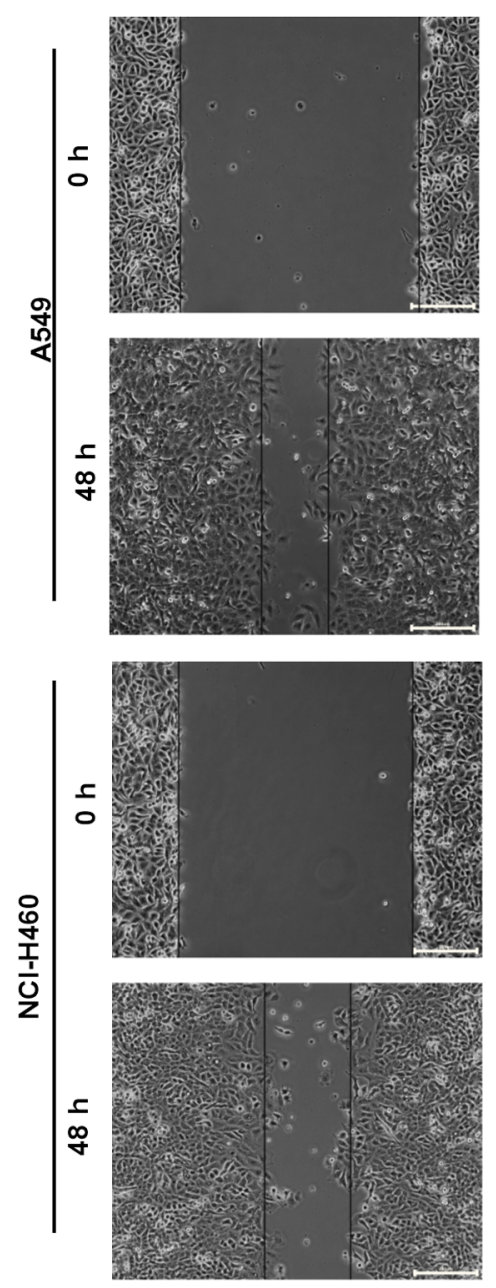

H

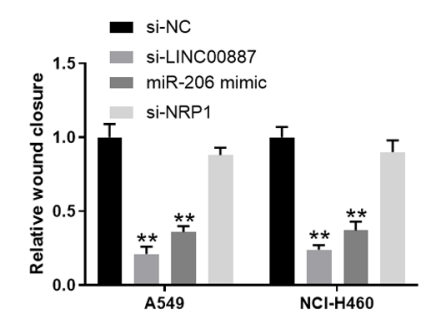

si-LINC00887
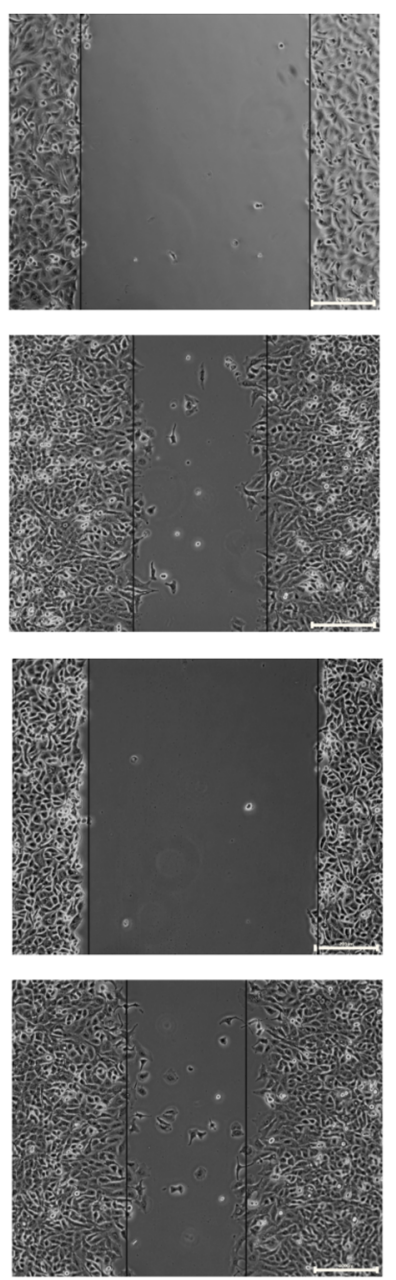

I

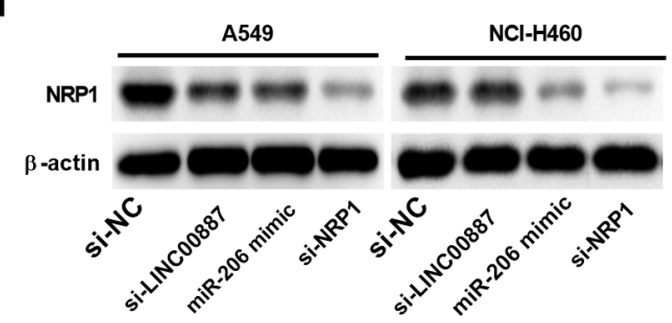

miR-206 mimic
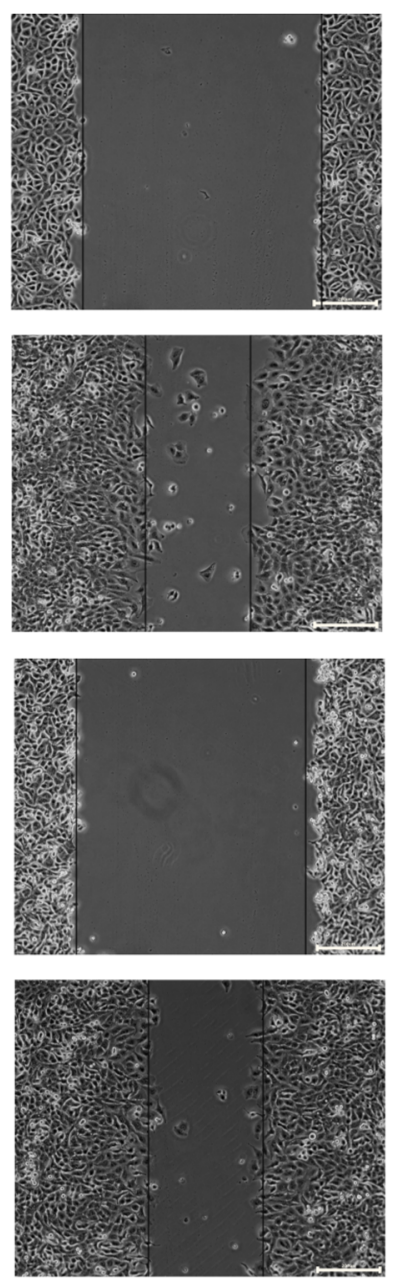

si-NRP1
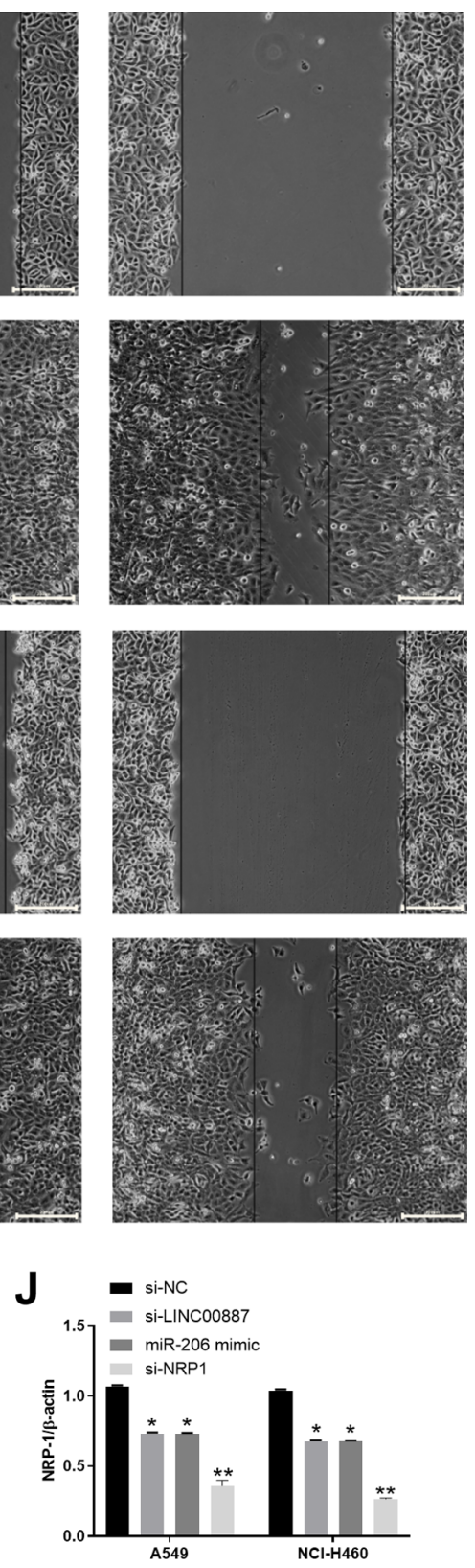

Figure 6. LINC00887-miR-206-NRP1 interaction network regulates lung carcinoma cell proliferation, migration and invasion. Lung carcinoma A549 or NCI-H460 cells were transfected with si-LINC00887, miR-206 mimic, si-NRP1 or si-NC. (A-C) Cell proliferation of (A) A549 and (B) NCI-H460 cells was assessed using the Cell Counting Kit-8 assay at the indicated time points, or (C) assessed by EdU and DAPI staining. (D) Transwell assays were used to analyze (E) migration and (F) invasion of A549 or NCI-H460 cells. Scale bar, $200 \mu \mathrm{m}$. (G and H) Cell migration capability was analyzed via wound-healing assay. Scale bar, $200 \mu \mathrm{m}$. (I and J) NRP1 protein expression was analyzed $72 \mathrm{~h}$ post transfection. The western blot experiments were repeated $\geq 3$ times independently. NRP1 expression was normalized to the expression levels of $\beta$-actin. Data are presented as the mean $\pm \mathrm{SD}$. " $\mathrm{P}<0.05$; ${ }^{* *} \mathrm{P}<0.01$ vs. NC. NC, negative control; miR, microRNA; NRP1, neuropilin 1; si, small interfering RNA; OD, optical density; EdU, 5'-ethynyl-2'-deoxyuridine.

and miR-206 expression in tumor tissues were examined. As presented in Fig. 7E and F, tumor tissues from the mice in the si-LINC00887 group exhibited significantly lower expression levels of LINC00887 and significantly higher expression levels of miR-206 compared with those in tissues from mice in the si-NC group. NRP1 protein levels were significantly downregulated in tumor tissues from the si-LINC00887 group compared with in tissues from the si-NC group (Fig. 7G and H). Overall, these results suggested that LINC00887 knockdown suppressed lung carcinoma growth in a xenograft model.

\section{Discussion}

Emerging studies have demonstrated that lncRNAs are important regulators that act as oncogenic or tumor suppressor molecules in various tumors $(17,39)$. For example, the metastasis-associated lung adenocarcinoma transcript 1 (MALAT1), also called NEAT2, is an abundant and highly conserved lncRNA across vertebrates. MALAT1 induces an EMT switch via the PI3K/AKT pathway in epithelial ovarian cancer (40). Moreover, MALAT1 expression has been reported to be a potential predictor of tumor 
A

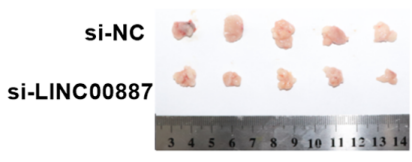

D

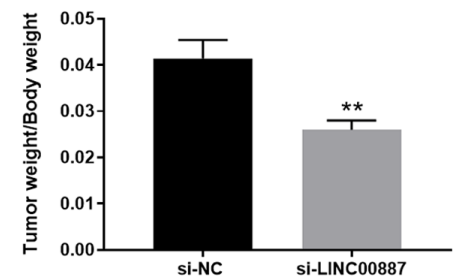

G

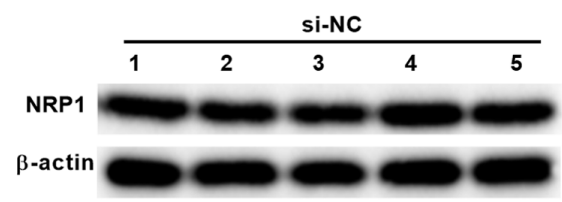

B

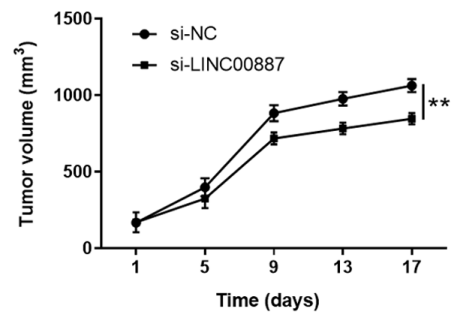

E
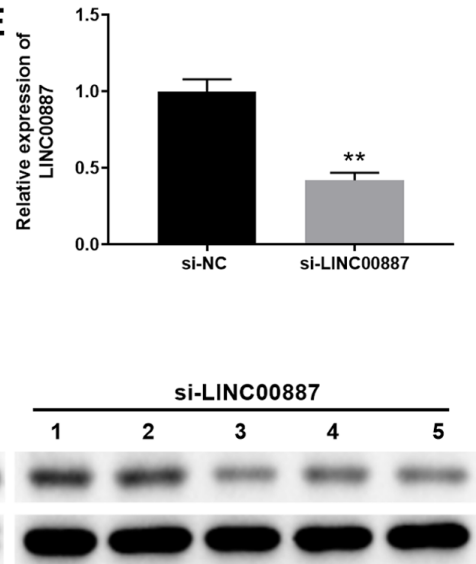

C

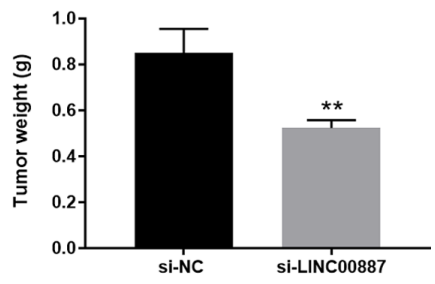

$\mathbf{F}$

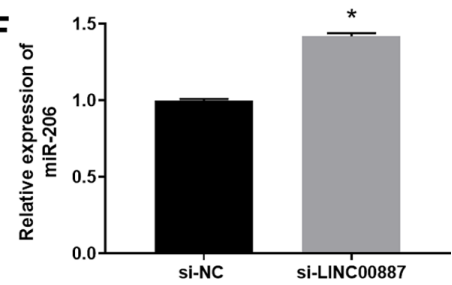

H

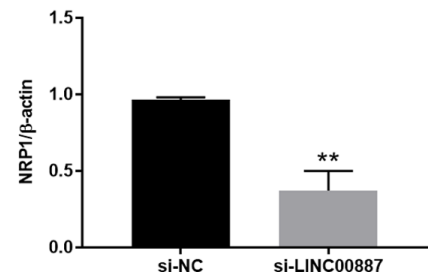

Figure 7. LINC00887 knockdown inhibits tumor growth of lung carcinoma in vivo. Lung carcinoma NCI-H460 cells were transfected with si-NC or si-LINC00887 and then implanted subcutaneously into nude mice to develop tumors. (A) Photographs of tumor tissues from si-NC or si-LINC00887 groups were taken on day 17. (B) Growth curve of tumor volume in nude mice were measured at the indicated time points. (C) Tumor weight and (D) tumor weight/body weight ratio in the si-NC or si-LINC00887 groups were measured on day 17. (E and F) The expression levels of (E) LINC00887 and (F) miR-206 in the tumor tissues from si-NC or si-LINC00887 groups were analyzed via reverse transcription-quantitative PCR. (G and H) Protein expression levels of NRP1 in tumor tissues from si-NC or si-LINC00887 groups were determined via western blotting. Data are presented as the mean $\pm \mathrm{SD}$. ${ }^{*} \mathrm{P}<0.05 ;{ }^{* *} \mathrm{P}<0.01 \mathrm{vs}$ si-NC. si, small interfering RNA; NC, negative control; miR, microRNA; NRP1, neuropilin 1.

metastasis and prognosis in CRC (41). Maternally expressed 3 was considered as a tumor suppressor and a potential therapeutic candidate in cervical tumors (42). IncRNAs exert their functions by sponging miRNAs via IncRNA-miRNA-mRNA regulatory axes (23-25). The present study extended the understanding of the IncRNA-miRNA-mRNA networks by revealing that LINC00887 directly interacted with miR-206, whereas miR-206 targeted NRP1 to promote the progression of lung carcinoma.

LINC00887 is a newly identified lncRNA involved in multiple types of cancer. Low LINC00887 expression levels have been observed in an invasive follicular thyroid carcinoma (43). A microarray analysis conducted by Zhu et al (44) has revealed that LINC00887 is one of the top 10 downregulated lncRNAs between stage II and stage III colorectal cancer. In human papillary thyroid cancer, a previous study has demonstrated that the expression levels of LINC00887 are upregulated compared with those in non-tumor thyroid tissues (45). Therefore, LINC00887 may function as an oncogenic IncRNA or a tumor suppressor in different types of tumors. In the present study, the expression levels of LINC00887 were upregulated in lung carcinoma tissues and cells compared with those in healthy tissues and cells; therefore, LINC00887 may act as an oncogene in lung cancer. Consistently, LINC00887 knockdown suppressed lung carcinoma cell proliferation, migration and invasion in vitro, as well as lung xenograft tumor growth in vivo.

Multiple miRNAs have been predicted as the potential targets of LINC00887, such as miR-138, miR-181 and miR-204 (45). In the present study, LINC00887 was identified to directly interact with miR-206. miR-206 has been reported as a tumor suppressor inhibiting cell proliferation, migration and invasion in gastric, colorectal, breast and laryngeal cancer (46-49). Furthermore, Samaeekia et al (50) have reported that miR-206 inhibits stemness and metastasis of breast cancer by regulating the myocardin-related transcription factor A/interleukin-11 signaling pathway. In the present study, the expression levels of miR-206 were downregulated in lung carcinoma tissues compared with those in healthy tissues, suggesting that it may be a tumor suppressor. Additionally, miR-206 overexpression inhibited lung carcinoma A549 or NCI-H460 cell proliferation, migration and invasion.

In the present study, NRP1 was identified as a direct target gene controlled by miR-206. NRP1 is a transmembrane glycoprotein that acts as a co-receptor for vascular endothelial growth factor and transforming growth factor- $\beta$, and is a promising novel target for chronic lymphocytic leukaemia therapy (51). NRP1 has been reported to be regulated by multiple miRNAs, such as miR-130, miR-141 and miR-338 in ovarian cancer, gastric cancer and pancreatic cancer (52-54). Additionally, a previous study has demonstrated that miR-206 regulates NRP1 expression in breast cancer (55). Consistently, the present study revealed that miR-206 regulated NRP1 expression by targeting the NRP1 3'-UTR in lung carcinoma cells. However, future studies are required to determine whether miR-206 has other targets and whether NRP1 is also regulated by multiple miRNAs in lung carcinoma. Bioinformatics analysis should be performed to analyze the association between the expression levels of LINC00887 and miR-206/NRP1 in patients with lung cancer in The Cancer Genome Atlas database. 
In conclusion, the results of the present study revealed that LINC00887 was upregulated in lung carcinoma tissues and cell lines. Furthermore, LINC00887 promoted lung carcinoma progression and metastasis by sponging miR-206 to regulate NRP1 expression. The xenograft tumor model experiment demonstrated that LINC00887 knockdown inhibited lung tumor growth in vivo. Overall, the LINC00887-miR-206-NRP1 axis may reveal a novel insight for lung tumorigenesis and may provide potential therapeutic strategies for patients with lung carcinoma.

\section{Acknowledgements}

Not applicable.

\section{Funding}

No funding was received.

\section{Availability of data and materials}

The datasets used and/or analyzed during the current study available from the corresponding author on reasonable request.

\section{Authors' contributions}

LBX and XPR conceived and designed the experiments. BXB, JX and YJR performed the experiments. DH and SHW analyzed and interpreted the data. LBX wrote the manuscript. XPR revised the manuscript. All the authors read and approved the final manuscript.

\section{Ethics approval and consent to participate}

Written informed consent was obtained from all patients. The present study was approved by the Ethics Committee of Shaanxi Provincial People's Hospital. The animal experiment was approved by the Institutional Animal Care and Use Committee of Shaanxi Provincial People's Hospital.

\section{Patient consent for publication}

Not applicable.

\section{Competing interests}

The authors declare that they have no competing interests.

\section{References}

1. Siegel RL, Miller KD and Jemal A: Cancer statistics, 2018. CA Cancer J Clin 68: 7-30, 2018.

2. Dela Cruz CS, Tanoue LT and Matthay RA: Lung cancer: Epidemiology, etiology, and prevention. Clin Chest Med 32: 605-644, 2011.

3. Bray F, Ferlay J, Soerjomataram I, Siegel RL, Torre LA and Jemal A: Global cancer statistics 2018: GLOBOCAN estimates of incidence and mortality worldwide for 36 cancers in 185 countries. CA Cancer J Clin 68: 394-424, 2018.

4. Tanase A, Colita A, Ianosi G, Neagoe D, Branisteanu DE, Calina D, Docea AO, Tsatsakis A and Ianosi SL: Rare case of disseminated fusariosis in a young patient with graft vs. host disease following an allogeneic transplant. Exp Ther Med 12: 2078-2082, 2016.
5. Ungureanu A, Zlatian O, Mitroi G, Drocaş A, Ţîrcă T, Călina D, Dehelean C, Docea AO, Izotov BN, Rakitskii VN, et al: Staphylococcus aureus colonisation in patients from a primary regional hospital. Mol Med Rep 16: 8771-8780, 2017.

6. Calina D, Rosu L, Roșu AF, Ianoşi G, Ianoşi S, Zlatian O, Mitruț R, Docea AO, Rogoveanu O, Mitruț P, et al: Etiological diagnosis and pharmacotherapeutic management of parapneumonic pleurisy. Farmacia 64: 946-952, 2016.

7. Lemjabbar-Alaoui H, Hassan OU, Yang YW and Buchanan P: Lung cancer: Biology and treatment options. Biochim Biophys Acta 1856: 189-210, 2015.

8. Siegel RL, Miller KD and Jemal A: Cancer statistics, 2019. CA Cancer J Clin 69: 7-34, 2019.

9. Knight SB, Crosbie PA, Balata H, Chudziak J, Hussell T and Dive C: Progress and prospects of early detection in lung cancer. Open Biol 7: 170070, 2017.

10. Daphedar A and Taranath TC: Characterization and cytotoxic effect of biogenic silver nanoparticles on mitotic chromosomes of drimia polyantha (Blatt. \& McCann) stearn. Toxicol Rep 5: 910-918, 2018.

11. Sani TA, Mohammadpour E, Mohammadi A, Memariani T, Yazd MV, Ramin R, Daniela C, Anca OD, Marina G, Etemad L and Shahsavand S: Cytotoxic and apoptogenic properties of Dracocephalum kotschyi aerial part different fractions on calu-6 and mehr-80 lung cancer cell lines. Farmacia 65: 189-199, 2017.

12. Saab AM, Guerrini A, Sacchetti G, Maietti S, Zeino M, Arend J, Gambari R, Bernardi F and Efferth T: Phytochemical analysis and cytotoxicity towards multidrug-resistant leukemia cells of essential oils derived from lebanese medicinal plants. Planta Med 78: 1927-1931, 2012.

13. Shao H, Jing K, Mahmoud E, Huang H, Fang X and Yu C: Apigenin sensitizes colon cancer cells to antitumor activity of ABT-263. Mol Cancer Ther 12: 2640-2650, 2013.

14. Zeng S, Kapur A, Patankar MS and Xiong MP: Formulation, characterization, and antitumor properties of trans- and cis-citral in the 4T1 breast cancer xenograft mouse model. Pharm Res 32: 2548-2558, 2015.

15. Forde PM, Brahmer JR and Kelly RJ: New strategies in lung cancer: Epigenetic therapy for non-small cell lung cancer. Clin Cancer Res 20: 2244-2248, 2014.

16. Mercer TR, Dinger ME and Mattick JS: Long non-coding RNAs: Insights into functions. Nat Rev Genet 10: 155-159, 2009.

17. Calle AS, Kawamura Y, Yamamoto Y, Takeshita F and Ochiya T: Emerging roles of long non-coding RNA in cancer. Cancer Sci 109: 2093-2100, 2018.

18. Sun H, Huang Z, Shheng W and Xu MD: Emerging roles of long non-coding RNAs in tumor metabolism. J Hematol Oncol 11: 106, 2018.

19. Sun M, Gadad SS, Kim DS and Kraus WL: Discovery, annotation, and functional analysis of long noncoding rnas controlling cell-cycle gene expression and proliferation in breast cancer cells. Mol Cell 59: 698-711, 2015.

20. Chakravarty D, Sboner A, Nair SS, Giannopoulou E, Li R, Hennig S, Mosquera JM, Pauwels J, Park K, Kossai M, et al: The oestrogen receptor alpha-regulated lncRNA NEAT1 is a critical modulator of prostate cancer. Nat Commun 5: 5383, 2014.

21. She K, Huang J, Zhou H, Huang T, Chen G and He J: lncRNA-SNHG7 promotes the proliferation, migration and invasion and inhibits apoptosis of lung cancer cells by enhancing the FAIM2 expression. Oncol Rep 36: 2673-2680, 2016.

22. Wu WK, Lee CW, Cho CH, Fan D, Wu K, Yu J and Sung JJ: MicroRNA dysregulation in gastric cancer: A new player enters the game. Oncogene 29: 5761-5771, 2010.

23. Lin $C$ and Yang L: Long noncoding RNA in Cancer: Wiring signaling circuitry. Trends Cell Biol 28: 287-301, 2018.

24. Zhang C, Wang C, Jia Z, Tong W, Liu D, He C, Huang X and Xu W: Differentially expressed mRNAs, lncRNAs, and miRNAs with associated co-expression and ceRNA networks in ankylosing spondylitis. Oncotarget 8: 113543-113557, 2017.

25. Fan CN, Ma L and Liu N: Systematic analysis of lncRNA-miRNA-mRNA competing endogenous RNA network identifies four-lncRNA signature as a prognostic biomarker for breast cancer. J Transl Med 16: 264, 2018.

26. Cong Z, Diao Y, Xu Y, Li X, Jiang Z, Shao C, Ji S, Shen Y, De W and Qiang Y: Long non-coding RNA linc00665 promotes lung adenocarcinoma progression and functions as ceRNA to regulate AKR1B10-ERK signaling by sponging miR-98. Cell Death Dis 10: 84, 2019.

27. Guo T, Li J, Zhang L, Hou W, Wang R, Zhang J and Gao P: Multidimensional communication of microRNAs and long non-coding RNAs in lung cancer. J Cancer Res Clin Oncol 145: 31-48, 2019. 
28. Liu S, Yan G, Zhang J and Yu L: Knockdown of long noncoding RNA (lncRNA) metastasis-associated lung adenocarcinoma transcript 1 (MALAT1) inhibits proliferation, migration, and invasion and promotes apoptosis by targeting miR-124 in retinoblastoma. Oncol Res 26: 581-591, 2018.

29. Wang D and Hu Y: Long non-coding RNA PVT1 competitively binds microRNA-424-5p to regulate CARM1 in radiosensitivity of non-small-cell lung cancer. Mol Ther Nucleic Acids 16: 130-140, 2018.

30. Yang X, Zhang W, Cheng SQ and Yang RL: High expression of lncRNA GACAT3 inhibits invasion and metastasis of non-small cell lung cancer to enhance the effect of radiotherapy. Eur Rev Med Pharmacol Sci 22: 1315-1322, 2018.

31. Yang J, Du YM and Li B: LncRNA BX357664 inhibits the proliferation and invasion of non-small cell lung cancer cells. Eur Rev Med Pharmacol Sci 23: 660-669, 2019.

32. Tian Y, Yu M, Sun L, Liu L, Huo S, Shang W, Sheng S, Wang J, Sun J, Hu Q, et al: Long noncoding RNA00887 reduces the invasion and metastasis of nonsmall cell lung cancer by causing the degradation of miRNAs. Oncol Rep 42: 1173-1182, 2019.

33. Ali MM, Akhade VS, Kosalai ST, Subhash S, Statello L, Meryet-Figuiere M, Abrahamsson J, Mondal T and Kanduri C: PAN-Cancer analysis of S-phase enriched IncRNAs identifies oncogenic drivers and biomarkers. Nat Commun 9: 883, 2018.

34. Travis WD, Brambilla E, Nicholson AG, Yatabe Y, Austin JH Beasley MB, Chirieac LR, Dacic S, Duhig E, Flieder DB, et al: The 2015 world health organization classification of lung tumors: Impact of genetic, clinical and radiologic advances since the 2004 classification. J Thorac Oncol 10: 1243-1260, 2015.

35. Livak KJ and Schmittgen TD: Analysis of relative gene expression data using real-time quantitative PCR and the 2(-Delta Delta C(T)) method. Methods 25: 402-408, 2001.

36. Salmena L, Poliseno L, Tay Y, Kats L and Pandolfi PP: A ceRNA hypothesis: The rosetta stone of a hidden RNA language? Cell 146: 353-358, 2011.

37. Kartha RV and Subramanian S: Competing endogenous RNAs (ceRNAs): New entrants to the intricacies of gene regulation. Front Genet 5: 8, 2014.

38. Paraskevopoulou MD, Vlachos IS, Karagkouni D, Georgakilas G, Kanellos I, Vergoulis T, Zagganas K, Tsanakas P, Floros E, Dalamagas T and Hatzigeorgiou AG: DIANA-LncBase v2: Indexing microRNA targets on non-coding transcripts. Nucleic Acids Res 44: D231-D238, 2016.

39. Balas MM and Johnson AM: Exploring the mechanisms behind long noncoding RNAs and cancer. Noncoding RNA Res 3 108-117, 2018.

40. Jin Y, Feng SJ, Qiu S, Shao N and Zheng JH: LncRNA MALAT1 promotes proliferation and metastasis in epithelial ovarian cancer via the PI3K-AKT pathway. Eur Rev Med Pharmacol Sci 21: 3176-3184, 2017

41. Ji Q, Zhang L, Liu X, Zhou L, Wang W, Han Z, Sui H, Tang Y, Wang Y, Liu N, et al: Long non-coding RNA MALAT1 promotes tumour growth and metastasis in colorectal cancer through binding to SFPQ and releasing oncogene PTBP2 from SFPQ/PTBP2 complex. Br J Cancer 111: 736-748, 2014.

42. Zhang J, Yao T, Wang Y, Yu J, Liu Y and Lin Z: Long noncoding RNA MEG3 is downregulated in cervical cancer and affects cell proliferation and apoptosis by regulating miR-21. Cancer Biol Ther 17: 104-113, 2016.
43. Celestino R, Nome T, Pestana A, Hoff AM, Gonçalves AP, Pereira L, Cavadas B, Eloy C, Bjøro T, Sobrinho-Simões M, et al: CRABP1, C1QL1 and LCN2 are biomarkers of differentiated thyroid carcinoma, and predict extrathyroidal extension. BMC Cancer 18: 68, 2018

44. Zhu H, Yu J, Zhu H, Guo Y and Feng S: Identification of key lncRNAs in colorectal cancer progression based on associated protein-protein interaction analysis. World J Surg Oncol 15: 153, 2017.

45. You X, Zhao Y, Sui J, Shi X, Sun Y, Xu J, Liang G, Xu Q and Yao Y: Integrated analysis of long noncoding RNA interactions reveals the potential role in progression of human papillary thyroid cancer. Cancer Med 7: 5394-5410, 2018.

46. Deng M, Qin Y, Chen X, Wang Q and Wang J: MiR-206 inhibits proliferation, migration, and invasion of gastric cancer cells by targeting the MUC1 gene. Onco Targets Ther 12: 849-859, 2019.

47. Sun P, Sun D, Wang X, Liu T, Ma Z and Duan L: MiR-206 is an independent prognostic factor and inhibits tumor invasion and migration in colorectal cancer. Cancer Biomark 15: 391-396, 2015.

48. Fu Y, Shao ZM, He QZ, Jiang BQ, Wu Y and Zhuang ZG: Hsa-MiR-206 represses the proliferation and invasion of breast cancer cells by targeting Cx43. Eur Rev Med Pharmacol Sci 19: 2091-2104, 2015

49. Zhang T,Liu M, Wang C, Lin C,Sun Y and Jin D: Down-Regulation of miR-206 promotes proliferation and invasion of laryngeal cancer by regulating VEGF expression. Anticancer Res 31: 3859-3863, 2011.

50. Samaeekia R, Adorno-Cruz V, Bockhorn J, Chang YF, Huang S, Prat A, Ha N, Kibria G, Huo D, Zheng H, et al: MiR-206 inhibits stemness and metastasis of breast cancer by targeting MKL1/IL11 pathway. Clin Cancer Res 23: 1091-1103, 2017.

51. Chaudhary B, Khaled YS, Ammori BJ and Elkord E: Neuropilin 1: Function and therapeutic potential in cancer. Cancer Immunol Immunother 63: 81-99, 2014.

52. Chen $\mathrm{C}, \mathrm{Hu}$ Y and Li L: NRP1 is targeted by miR-130a and miR-130b, and is associated with multidrug resistance in epithelial ovarian cancer based on integrated gene network analysis. Mol Med Rep 13: 188-196, 2016.

53. Peng Y, Liu YM, Li LC, Wang LL and Wu XL: MicroRNA-338 inhibits growth, invasion and metastasis of gastric cancer by targeting NRP1 expression. PLoS One 9: e94422, 2014.

54. Ma L, Zhai B, Zhu H, Li W, Jiang W, Lei L, Zhang S, Qiao H, Jiang $X$ and Sun X: The miR-141/neuropilin-1 axis is associated with the clinicopathology and contributes to the growth and metastasis of pancreatic cancer. Cancer Cell Int 19: 248 , 2019.

55. Seifi-Alan M, Shams R, Bandehpour M, Mirfakhraie R and Ghafouri-Fard S: Neuropilin-1 expression is associated with lymph node metastasis in breast cancer tissues. Cancer Manag Res 10: 1969-1974, 2018.

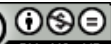

This work is licensed under a Creative Commons Attribution-NonCommercial-NoDerivatives 4.0 International (CC BY-NC-ND 4.0) License. 